\title{
Evaluating the multiple benefits of a sustainable drainage scheme in Newcastle, UK
}

1 Emily C. O'Donnell PhD

Research Fellow, School of Geography, University of Nottingham, Nottingham, UK (corresponding author: emily.o'donnell@nottingham.ac.uk)

2 Richard Woodhouse BA Hons Asset Delivery Programme Manager, Northumbrian Water Group, Durham, UK
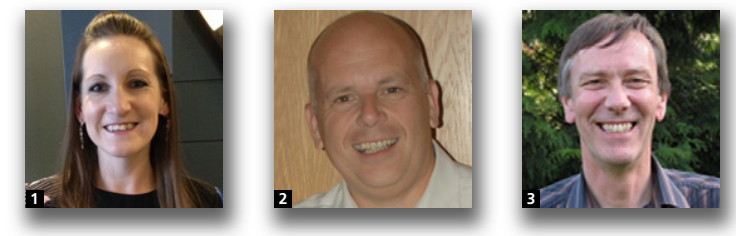

3 Colin R. Thorne PhD

Chair of Physical Geography, School of Geography, University of Nottingham, Nottingham, UK

Sustainable drainage systems and 'blue-green' infrastructure provide a range of environmental, economic and social benefits in addition to managing water quantity and quality. Recognition of the multi-functionality of these systems and their multiple benefits could lead to joint efforts to deliver infrastructure that meets the strategic objectives of both public and private organisations. This paper reports on the evaluation of the multiple benefits of the Killingworth and Longbenton surface water management scheme, a partnership project in north-east England jointly funded by Northumbrian Water, the Environment Agency and North Tyneside Council. Using complementary assessment tools, the evaluation quantified and monetised six key benefits, assessed two qualitative benefits, illustrated the spatial distribution of five non-flood benefits and highlighted locations with the greatest opportunity for multi-beneficial intervention. It was found that the scheme generates significant flood damage reduction benefits, improves water quality, habitat size, carbon dioxide sequestration and amenity, and reduces noise pollution. Use of the tools for multiple benefit evaluation shows promise as an aid to facilitate partnership working towards implementation of multi-functional sustainable drainage systems and blue-green infrastructure.

\section{Introduction}

Sustainable drainage systems (SuDS) and 'blue-green' infrastructure (BGI) are gaining momentum in the UK as alternatives to traditional piped drainage systems to manage surface water and flood risk. For instance, several lead local flood authorities and water companies are looking towards bluegreen sustainable drainage solutions that remove, store, divert and delay surface water runoff, while using water as a resource to generate multiple benefits, for example Welsh Water's 'Rainscape' initiative (WW, 2016), Thames Water's sustainable drainage schemes (TW, 2016) and Northumbrian Water's 'Rainwise' surface water management programme (NW, 2016). SuDS are also identified in the Environment Agency (EA) and Ofwat's drainage strategy framework as low-regret interventions that are adaptable and robust under a range of possible futures (EA and Ofwat, 2013). In addition to managing water quantity and quality, and providing benefits when inundated with water (e.g. during rainfall events), BGI and SuDS also generate multiple environmental, social and economic benefits from multi-functional use of blue-green spaces under nonflood conditions (Woods Ballard et al., 2015). BGI may enhance the visual quality of the urban environment in addition to providing biophysical functions such as carbon dioxide sequestration (Getter et al., 2009), urban cooling (Hardin and Jensen, 2007), air pollutant absorption (Brack, 2002) and improved wildlife and biodiversity (Tzoulas et al., 2007). Communities in blue-green environments may become healthier (Coutts, 2016), and schemes are designed to be sustainable by making them resilient and adaptive to future changes in, for example, climate and landuse (Lennon and Scott, 2014). BGI and SuDS can therefore provide a range of ecosystem services, including regulating services (benefits obtained from the regulation of ecosystem processes such as water and air quality), supporting services (necessary for the production of other ecosystem services, e.g. soil formation), cultural services (non-material benefits obtained from ecosystems, e.g. aesthetic experience) and, to a lesser extent, provisioning services (products obtained from ecosystems) (UKNEA, 2011). BGI and SuDS can also help extend the lifetime of subsurface sewer networks by managing water on the surface, thus increasing network capacity.

The provision of a wide range of benefits suggests that BGI and SuDS may help meet the strategic objectives of departments within public (e.g. local authorities, EA) and private (e.g. water companies) sector organisations, while engendering 
greater support from local communities who often value the environmental and social benefits more highly (Everett et al., 2015). However, SuDS and BGI schemes tend not to be designed to maximise the provision of multiple benefits, but instead typically address one or two objectives, for example surface water management (Newell et al., 2013; Stovin et al., 2013). In many local authorities, SuDS and BGI frequently remain entrenched within water and flood management departments and, despite major investment and research into multi-functionality (e.g. the updated SuDS Manual (Woods Ballard et al., 2015) and the Benefits of SuDS Tool (BeST) (CIRIA, 2015)), potential multi-functionality is not universally acknowledged.

Collaborative working and co-funding may be the optimal approach to create multi-functional, multi-beneficial and resilient infrastructure (O’Donnell et al., 2017). The specific benefits that may accrue to different beneficiaries need to first be identified, communicated and accepted by all stakeholders involved. While many multiple benefits have been reported in the literature (Ashley et al., 2013; Ellis, 2013; Jose et al., 2015), they are often valued notionally and so difficult to include in funding proposals and thus implement widely (Ashley et al., 2015; O'Donnell et al., 2017; Thorne et al., 2015). To address this need, new tools and methodologies have been developed to evaluate BGI and $\mathrm{SuDS}$, for example lifecycle assessment (Casal-Campos et al., 2015), geographic information system (GIS) evaluation (Hoang et al., 2016; Morgan and Fenner, 2017; Norton et al., 2015) and spreadsheet monetisation (CIRIA, 2015).

In this study, BeST (CIRIA, 2015) and the Blue-Green Cities multiple benefits GIS toolbox (BGC, 2016) were used to evaluate the impact of the Killingworth and Longbenton surface water management scheme. This partnership project in the north-east of England, jointly funded by Northumbrian Water, the EA and North Tyneside Council, aims to remove surface water from the sewer network and return it to the natural environment through blue-green and grey interventions (NWCP, 2016). Six benefits, including flood damage reduction (the primary objective of the scheme), are quantified and monetised, and the spatial distribution and intensity of five non-flood biophysical benefits are demonstrated, illustrating how the benefit intensity (illustrating the extent and distribution of single or cumulative benefits) may change spatially in response to local environmental factors. Two qualitative benefits are assessed, and locations that have the greatest opportunity for improvement are highlighted by calculating the potential benefits. Utilisation of these complementary tools for multiple benefit evaluation shows promise as an aid to facilitate partnership working towards implementation of multi-functional BGI, with potential application in the public and private sectors.

\section{Multiple benefit evaluation}

The multiple benefits GIS toolbox and BeST provide an indication of the likely benefits (and disbenefits) associated with a
SuDS or BGI project, which can then be supplemented by locally specific analyses. Both tools can be used to evaluate planned developments (to compare the benefits of a SuDS or BGI option against conventional drainage) and retrofits (comparing new options against the existing baseline). While the tools are complementary and provide outputs in several formats, the outputs should not be directly compared due to the use of different calculations, methodologies, time frame of evaluations and units to represent the benefits.

\subsection{Benefits of SuDS Tool (BeST)}

BeST is an Excel-based decision-support tool that provides a structured approach to evaluating a wide range of potential benefits of different courses of action (CIRIA, 2015). BeST provides a robust economic appraisal for different drainage options without the need for full-scale economic inputs. The benefits are considered over a specific time frame (specified by the user), providing insight into how benefits may accrue over time and at different rates. A wide range of benefits are first screened and those likely to generate significant benefits are identified for further detailed assessment. The most significant benefits can be selected by the user for quantification and monetisation. BeST currently considers 20 benefits based on the UK National Ecosystem Assessment's ecosystem service approach (UKNEA, 2011), seven of which are qualitative (Table 1). Additional benefits (and disbenefits) can also be captured through user input values. Site-specific information is required to run the tool, with the outputs dependent on the quality and level of detail; locally derived and site-specific quantities and monetary values will provide a more robust assessment with fewer assumptions. There are several options within each benefit category to calculate the impact of the proposal on the given benefit. For instance, benefits to air quality may be calculated by directly entering the area of proposed SuDS and the number of trees planted and using the vegetation pollution removal levels. Alternatively, if the impact of the proposal on air quality has already been calculated, the net present values can be entered directly. A matrix approach that considers the magnitude and area of the impact of the scheme is used to evaluate the qualitative benefits. Monetary valuation of the benefits is predominately based on a value transfer approach, with future benefits discounted $(3 \cdot 5 \%$ discount rate) (HM Treasury, 2003). BeST also considers the uncertainty associated with benefit quantification and monetisation through user-defined confidence levels. At the end of the process, monetised benefits are categorised according to an ecosystem services framework and triple bottom line criteria.

\subsection{Multiple benefits GIS toolbox}

The multiple benefits GIS toolbox demonstrates the spatial distribution of the benefits (and disbenefits) of BGI and how their intensity changes with distance from the infrastructure, illustrating how benefits may radiate out from the site of intervention (Hoang et al., 2016; Morgan and Fenner, 2017). The GIS toolbox considers the local context and provides 
Table 1. Summary of the multiple benefit evaluation tools

\begin{tabular}{|c|c|c|}
\hline Benefit categories & Tool inputs & Tool outputs \\
\hline \multicolumn{3}{|c|}{ Multiple benefits GIS toolbox (BGC, 2016; Morgan and Fenner, 2017) } \\
\hline Flood damage & OS Mastermap & \multirow{2}{*}{$\begin{array}{l}\text { Benefit intensity maps (for single } \\
\text { and multiple benefits) }\end{array}$} \\
\hline reduction & OS Integrated Transport Network & \\
\hline Noise mitigation & Flood depth and extent data from a flood inundation model & Multiple benefit profile \\
\hline Air pollution reduction & Building class data & \multirow{2}{*}{$\begin{array}{l}\text { Potential benefit maps (for single } \\
\text { and multiple benefits) }\end{array}$} \\
\hline Carbon sequestration & Terrain data, for example OS Terrain $5 \mathrm{~m}$ Digital Terrain Model & \\
\hline Habitat size & Shapefile of SuDS interventions & \multirow{2}{*}{$\begin{array}{l}\text { Benefit effectiveness maps } \\
\text { (for single and multiple benefits) }\end{array}$} \\
\hline Access to greenspace & & \\
\hline \multicolumn{3}{|c|}{ Benefits of SuDS Tool (BeST) (CIRIA, 2015) } \\
\hline Air quality & Type and size of SuDS & \multirow{2}{*}{$\begin{array}{l}\text { Monetised summary of outputs } \\
\text { (pre and post confidence) }\end{array}$} \\
\hline Amenity & Present value of impacts (if this has already been calculated) & \\
\hline Biodiversity and & - A wide range of data, including flood inundation data or flood & Summary of qualitative outputs \\
\hline Building temperature & habitat type), health impacts (e.g. views over greenspace), & service categories (pie chart, \\
\hline Carbon reduction and & socio-economic data (e.g. number of residents living in area, & bar charts) \\
\hline sequestration & house prices), drainage data (e.g. total reduction in water use) & Summary results - triple bottom \\
\hline Crime $^{\mathrm{a}}$ & Confidence level in calculated method and valuation & line categories (pie chart, bar \\
\hline Economic growth ${ }^{\mathrm{a}}$ & Evaluation time frame & charts) \\
\hline Education $^{\mathrm{a}}$ & & Benefit-cost ratio \\
\hline Enabling development ${ }^{\mathrm{a}}$ & & Flexibility scores \\
\hline $\begin{array}{l}\text { Flexible infrastructure }{ }^{a} \\
\text { (under development) }\end{array}$ & & - Sensitivity analysis \\
\hline Flooding & & \\
\hline Groundwater recharge & & \\
\hline Health & & \\
\hline Pumping wastewater & & \\
\hline Rainwater harvesting & & \\
\hline Recreation & & \\
\hline Tourism $^{a}$ & & \\
\hline Traffic calming ${ }^{a}$ & & \\
\hline Treating wastewater & & \\
\hline Water quality & & \\
\hline User-defined benefits & & \\
\hline
\end{tabular}

location-specific evaluations of the spatial extent of benefits that are dependent on the pre-existing environmental conditions. For instance, the benefits of a BGI project in a densely residential area with limited current greenspace will generate a different benefit profile and spatial distribution to the same project in an area with abundant greenspace. Benefits are normalised to a common scale to allow different benefit types to be compared and to demonstrate the benefit uplift relative to the reference condition. The GIS toolbox currently considers six biophysical benefits (Table 1) and calculates benefits for a static point in time. The multiple benefits of the intervention are calculated by combining the outputs of single benefit layers into a cumulative benefit intensity map, illustrating where the scheme creates the most improvement and where benefits can be co-optimised. The GIS toolbox can also be used to calculate the potential benefits and the effectiveness of the modelled interventions. Effectiveness assesses whether the scheme could make a significant difference to the area when compared with the benefits that the area provides under the reference scenario. Potential benefit scores evaluate where the best opportunities for improvements are within an area, demonstrating where interventions might generate the most single and multiple benefits. The full method is described by Morgan and Fenner (2017).

\section{Killingworth and Longbenton surface water management scheme}

Northumbrian Water, the EA and North Tyneside Council worked in partnership on a jointly funded surface water management project in Killingworth and Longbenton, situated on the rural-urban fringe in North Tyneside (NWCP, 2016). The project (July 2016-December 2016) aimed to reduce local flood risk, improve water quality (due to fewer combined sewer overflows (CSOs)) and increase network capacity and scope for population growth and development. This will be achieved by removing surface water from the sewer network and returning it to the natural environment via a combination of blue-green and grey infrastructure, comprising

a new $1050 \mathrm{~mm}$ underground overflow pipe from Killingworth Lake to the West Moor tributary

- the creation of five surface attenuation basins for surface water storage during heavy rainfall - one along the south side of Killingworth Lake (Figure 1), one in the grounds of 


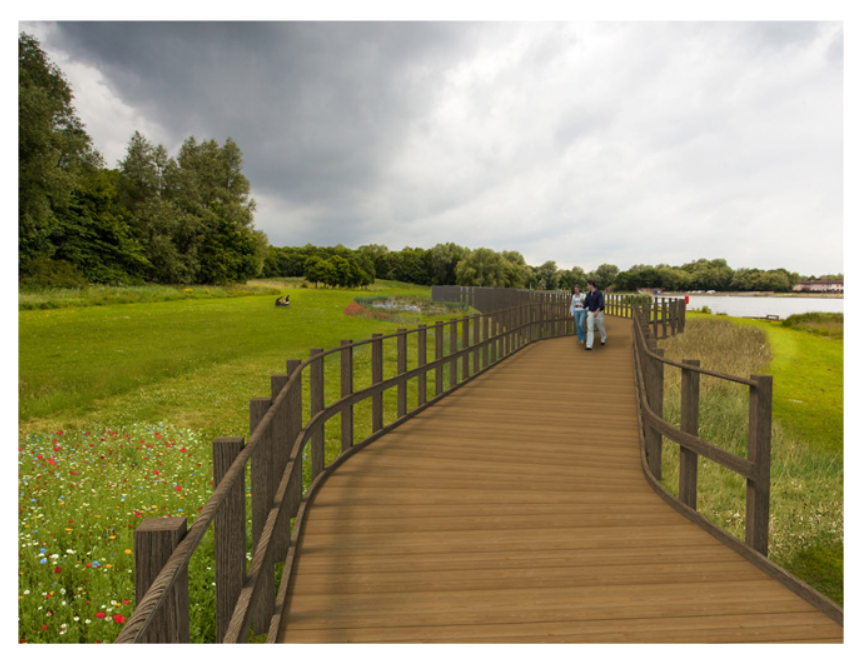

Figure 1. Artist's impression of the Killingworth Lake attenuation basin with raised path

Longbenton Community College, adjacent to Forest Hall Letch (Figure 2), and three smaller basins along Forest Hall Letch on Killingworth Moor

- disconnection of Longbenton Letch from the combined sewerage network and diversion into Forest Hall Letch (Figure 3).

The location and dimensions of the five attenuation basins are illustrated in Figure 4. A raised path was included as part of the Killingworth Lake intervention (Figure 1) to encourage recreation activity after the SuDS installation, thus maintaining accessibility. The attenuation basin in the grounds of Longbenton Community College (currently a sports field) will remain accessible by the creation of a SuDS amphitheatre for use during non-flood conditions (Figure 2). Killingworth

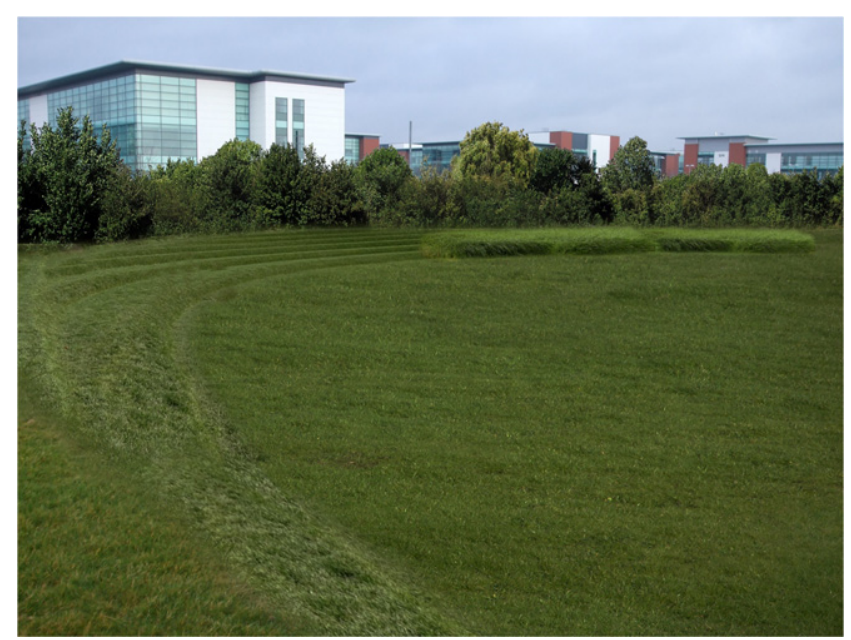

Figure 2. Artist's impression of the SuDS amphitheatre in Longbenton Community College grounds

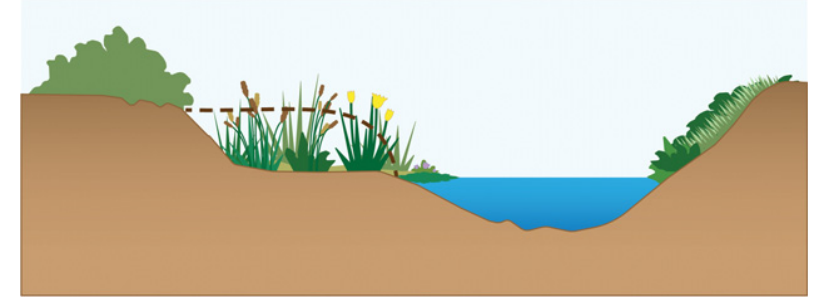

Figure 3. Design of the managed flood plain in the upper reaches of Longbenton Letch (source: Drawing Attention, RRC)

Moor is private land and not currently accessible to the public; the new attenuation basins will remain non-accessible.

\section{Methods}

The multiple benefits of the Killingworth and Longbenton surface water management scheme were evaluated using BeST and the GIS toolbox. Detailed flood inundation modelling conducted by Northumbrian Water is included in the BeST evaluation through a comprehensive assessment using the multi-coloured manual (Penning-Rowsell et al., 2014). This generates an expected benefit arising from reduced flood risk, and considers the grey and blue-green intervention measures. The BeST evaluation was completed by MWH on behalf of Northumbrian Water. Detailed flood depth and extent data were not available for input into the GIS toolbox (to calculate the spatial distribution of flood damage avoided) and hence the GIS toolbox was used to evaluate the non-flood environmental benefits of the five attenuation basins.

\subsection{BeST set up}

The July 2015 version of BeST was run in Microsoft Excel. Initial screening suggested that eight quantitative benefits (including two disbenefits) and two qualitative benefits would be generated by the scheme at a low risk of double counting. These were amenity, biodiversity and ecology, education, enabling development, flooding, recreation, vehicle damage avoided (user-defined), water quality, loss of crops/revenue (disbenefit, user-defined), and noise and disruption (disbenefit, user-defined). Most benefits were evaluated over a 40-year time frame (Table 2). Flood damage reduction was calculated over a 100 -year period to provide the best cost-benefit value return. Amenity was calculated as a one-off benefit for the year after installation (2017) and reflects expected property price increases as a result of public greenspace enhancement. Vehicle damage avoided was also calculated as a one-off benefit, while noise and disruption from the construction work was thought to impact local residents in 2016 only. The selected confidence levels used for the calculations and valuations are based on available data, BeST guidance and expert judgement. The post-confidence data are presented in Section 5 to account for some of the assumptions and simplified approaches used to 


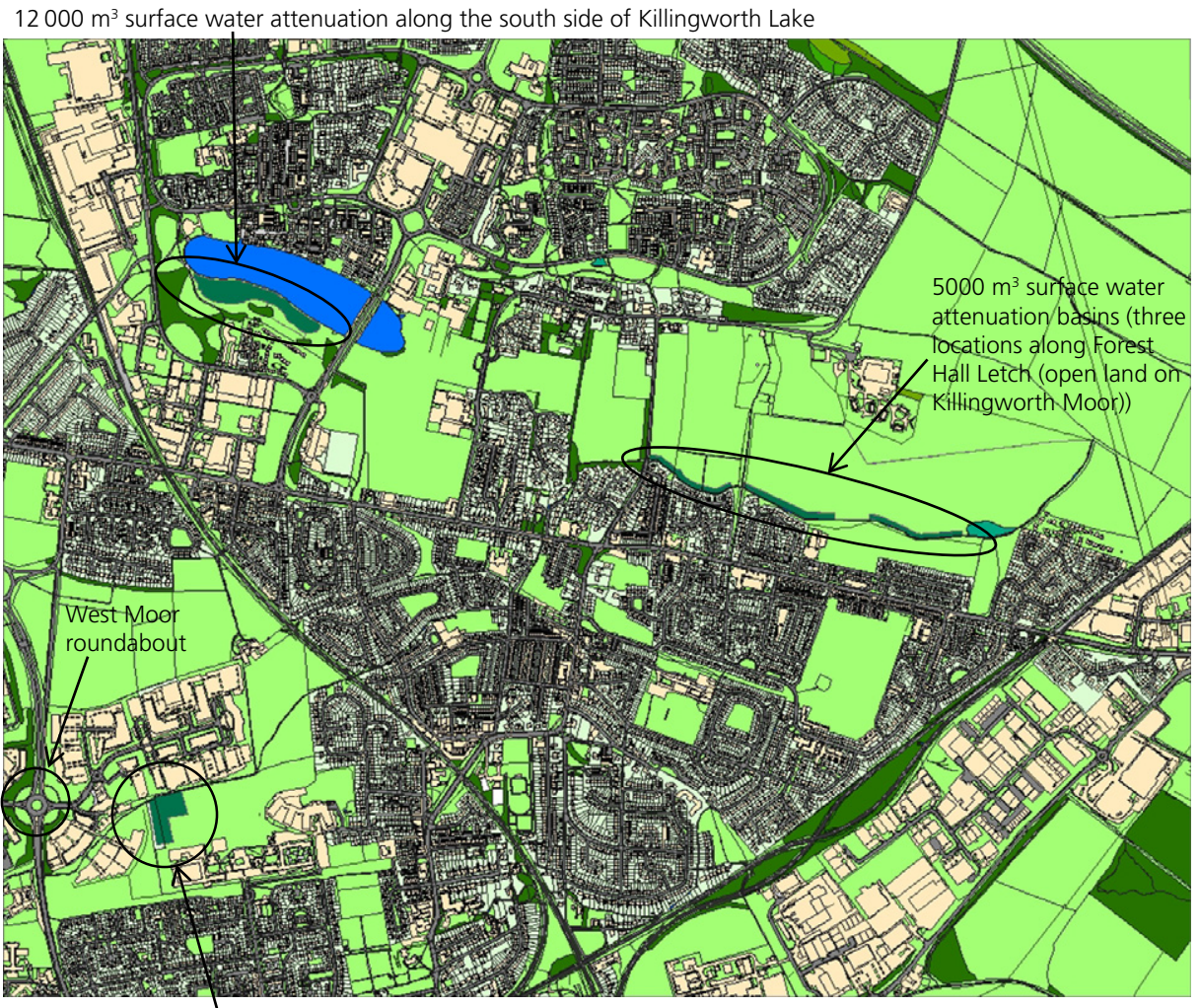

$5000 \mathrm{~m}^{3}$ surface water attenuation basin (grounds of Longbenton Community College)

Figure 4. Location of SuDS schemes in Killingworth and Longbenton

Table 2. Monetary benefits derived from BeST for the Killingworth and Longbenton surface water management scheme

\begin{tabular}{|c|c|c|c|}
\hline Benefit category & Ecosystem Service & $\begin{array}{l}\text { Time period of } \\
\text { evaluation }\end{array}$ & $\begin{array}{l}\text { Monetary benefit (present value } \\
\text { after confidence): } \mathbf{f}\end{array}$ \\
\hline \multicolumn{4}{|l|}{ Benefits } \\
\hline Flooding & Regulating & $2015-2115$ & 49837505 \\
\hline Water quality & Regulating & 2015-2055 & 1105345 \\
\hline Recreation & Cultural & 2015-2055 & 240605 \\
\hline Amenity & Cultural & 2017 & 100292 \\
\hline Vehicle damage avoided & Regulating & 2016-2017 & 40004 \\
\hline Biodiversity and ecology & Supporting & $2015-2055$ & 32928 \\
\hline \multicolumn{4}{|l|}{ Disbenefits } \\
\hline Loss of crops/revenue & Provisioning & $2015-2055$ & -120797 \\
\hline Noise and disruption & Cultural & 2016-2017 & -17408 \\
\hline
\end{tabular}

calculate the benefits. The resultant monetised benefits should thus be regarded as conservative.

\subsection{GIS toolbox}

The multiple benefits were evaluated using ArcGIS 10.3.1 and the Blue-Green Cities toolbox add-in (BGC, 2016). Benefits were calculated over an $8.74 \mathrm{~km}^{2}$ site that encompassed the interventions and the local environment, and allowed the wider benefits to be captured. The OS Mastermap topographic layer was edited to account for the new SuDS features (attenuation basins)
Killingworth Lake: natural surface (reference scenario) to marsh reeds (BGI scenario)

- Longbenton Community College: natural surface (reference scenario) to rough grassland (BGI scenario)

- Killingworth Moor: natural surface (reference scenario) to rough grassland (BGI scenario).

Characteristic modelling first created rasters showing the spatial distribution of the physical characteristic of interest, for example levels of carbon dioxide sequestration, for reference and BGI scenarios. The outputs were then normalised as part 
of the single benefit evaluations that were completed for each benefit category. Finally, the multiple benefit evaluation was run to combine the single benefits, assuming that all benefits were equally weighted.

\section{Quantitative and monetised benefits}

Evaluation of the multiple benefits of the Killingworth and Longbenton surface water management scheme using BeST showed that flood damage reduction benefits of up to $£ 50$ million could accrue over the 100-year evaluation period (Figure 5(a), Table 2). This regulating ecosystem service accounted for $97 \%$ of the benefits provided by the scheme. The flood benefits are primarily attributed to reduced propertylevel flooding and suggest that the underground pipe, flow diversion and additional surface storage provided by the attenuation basins would significantly reduce peak flows in the downstream sewer and drainage systems. Reduced flooding at West Moor roundabout is also estimated to reduce traffic disruption and save $300 \mathrm{~h}$, which accounts for $£ 87000$ of the flood damage reduction benefits. Vehicle damage avoided as a result of reduced flooding creates a further $£ 40000$ of benefits. The scheme is also expected to improve water quality (regulating ecosystem service) and create $£ 1 \cdot 1$ million of benefits. This is predominantly due to an expected change in the water quality classification from moderate to good owing to upstream improvements in Forest Hall Letch, daylighting of
Longbenton Letch, improvement to the Ouseburn (which the letches supply), and reduction of CSOs.

The scheme also created several cultural ecosystem services, primarily recreational improvements, which were estimated to create almost $£ 241000$ of benefits over the 40-year evaluation period (Figure 5(b)). Reduced CSOs, improved water quality in the letches and the green attenuation areas themselves are expected to make the area more attractive for local residents and other users, in addition to reducing odour and increasing recreational opportunities. Data on the use of Killingworth Lake or the letches for recreation were not available so a proxy estimate based on the number of visits to Jesmond Dene (a public park in east Newcastle) was used. An increase in visitors of $2 \%$ was expected if the unpleasant smell from the Ouseburn was removed (NCC, 2012), resulting in an annual increase in visits to the area of almost 22000 . Amenity (cultural ecosystem service) accounted for $£ 100000$ of benefits, reflecting expected increases in property prices as a result of public open greenspace enhancements and improved attractiveness of the area, in particular, around Forest Hall Letch. The prices of 300 homes are expected to be positively impacted.

The final benefit provided by the scheme was a supporting ecosystem service relating to biodiversity and ecology. The scheme has the opportunity to improve wildlife habitat in the attenuation areas along Forest Hall Letch and Longbenton Letch,

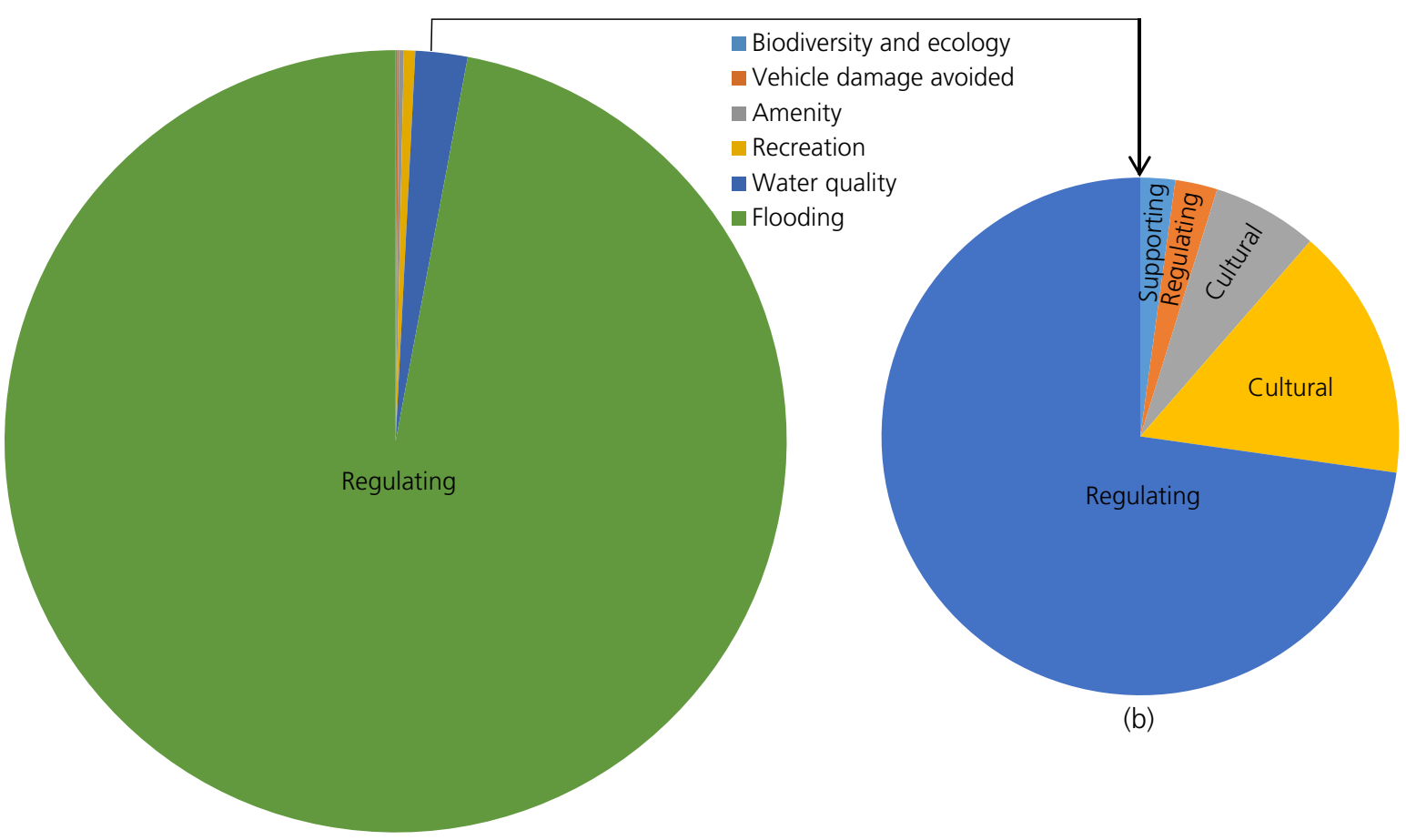

(a)

Figure 5. (a) Positive individual benefits (present value, post-confidence) of the Killingworth and Longbenton surface water management scheme using an ecosystem services framework. (b) Positive individual benefits excluding flood damage reduction 
and potentially enhance Gosforth Park Nature Reserve due to improved flow from Killingworth Lake. The 1.7 ha newly created habitat from the scheme accounts for $£ 33000$ of benefits.

The monetised disbenefits were negligible compared with the net benefits. Noise and disruption throughout the implementation phase are assumed to affect 300 residents near to the construction works, at an annual cost of $£ 58.17$ per household (DfT, 2012). Loss of crops/revenue due to the replacement of $\sim 9200 \mathrm{~m}^{2}$ agricultural land on Killingworth Moor with attenuation basins creates a disbenefit of more than $£ 120000$ based on the value of unequipped arable land ( $£ 12$ 227/ha) in Northumberland (GVO, 2011).

\section{Qualitative benefits}

The BeST output suggests that the interventions may create a small improvement with regard to enhancing education, based on a medium magnitude of impact and medium size of area to be impacted. This is primarily due to one of the attenuation basins being situated in the grounds of Longbenton Community College, leading to direct educational opportunities, for example for the nearby Benton Dene Primary School.

Drainage capacity is currently a barrier to growth and development in the North Tyneside region and hence there is potential for the scheme to help enable development. However, there is currently no evidence to suggest that additional land may become available due to this scheme, and limited information on how other socio-economic and environmental factors may influence development. The level of confidence in this benefit is therefore low, and negligible to little improvement to development capacity is expected.

\section{Spatial distribution of non-flood benefits}

The GIS evaluation concentrated on the non-flood environmental benefits of the five attenuation basins (using five pre-set benefit categories). Demonstration of these benefits to communities may increase the support for flood risk management schemes. This is particularly relevant in areas that are not currently at flood risk but where the interventions are designed to protect downstream locations, as local communities will likely feel that they are also benefitting from the scheme.

The GIS toolbox is designed to demonstrate maximum benefits when an area changes from built infrastructure to natural infrastructure. Therefore, the Killingworth and Longbenton SuDS only generate low-medium intensity benefits in the five categories analysed here because the evaluation site has a large proportion $(47 \%)$ of existing greenspace. The small benefits that do accrue are primarily due to changes in greenspace type at the intervention site, for example from natural surface to rough grassland in the grounds of Longbenton Community College. Wider spatial impacts are minimal due to the abundance of existing greenspace. The tool only distinguishes between the landuse categories designated by OS Mastermap input data (e.g. grassland, scrub, coniferous or non-coniferous trees) and does not consider quality or health of greenspace. Application of the GIS toolbox in dense residential and commercial areas is presented by Morgan and Fenner (2017). The multiple benefits presented here are thus expected to be highly conservative.

\subsection{Multiple benefits}

The Killingworth and Longbenton attenuation basins created a range of low-medium intensity benefits concentrated at the sites of intervention (Figure 6, in which the colour coding and scale refer to the normalised benefit (negative values refer to disbenefits and positive values refer to benefits)). Some of the multiple benefits spread to adjacent areas, such as around Killingworth Lake, the grounds of Longbenton Community College, Benton Dene Primary School and residential areas to the east of the school. The relative performance of each benefit in terms of magnitude ( $y$-axis) and area over which the benefit has influence ( $x$-axis) is illustrated in Figure 7 , where the size of the bubbles reflects the effectiveness of the intervention in generating the benefit. The largest benefit scores were observed in the habitat category, which positively impacted $0 \cdot 11 \mathrm{~km}^{2}$ of the study area. An increase in habitat size by the scheme was also the most effective benefit. This was followed by carbon dioxide sequestration and air pollution reduction, which both created benefits to $0.04 \mathrm{~km}^{2}$ of the study area. The benefit to noise pollution reduction positively impacted the largest area $\left(0 \cdot 15 \mathrm{~km}^{2}\right)$ but at a relatively low intensity and was not very effective. The attenuation basins did not change access to greenspace so no benefit or disbenefit was observed.

\subsection{Single benefits}

Figure 8 illustrates the spatial distribution of each individual benefit (and normalised benefit score). The greatest improvements in habitat size were observed at the intervention sites due to a change in landuse type (Figure 8(a)). Benefits were also observed around Killingworth Lake, where the attenuation basins connect with existing habitat and form a new habitat corridor that results in greater ecosystem services (Mitchell et al., 2013). The existing habitat networks around the other sites of intervention already offer benefits that are not significantly increased by the interventions. In practice, the higher quality of greenspace associated with the attenuation basins would likely improve habitats further, yet this is not captured by the tool.

The change in greenspace type also generated carbon dioxide sequestration and air pollution benefits at the intervention sites (Figures 8(b) and 8(c)). The tool selects all natural surfaces and assigns a carbon dioxide sequestration value based on the type of vegetation. The new types of greenspace associated with the attenuation basins had a greater sequestration rate 
Water Management

Volume 171 Issue WM4
Evaluating the multiple benefits of a

sustainable drainage scheme in

Newcastle, UK

O'Donnell, Woodhouse and Thorne

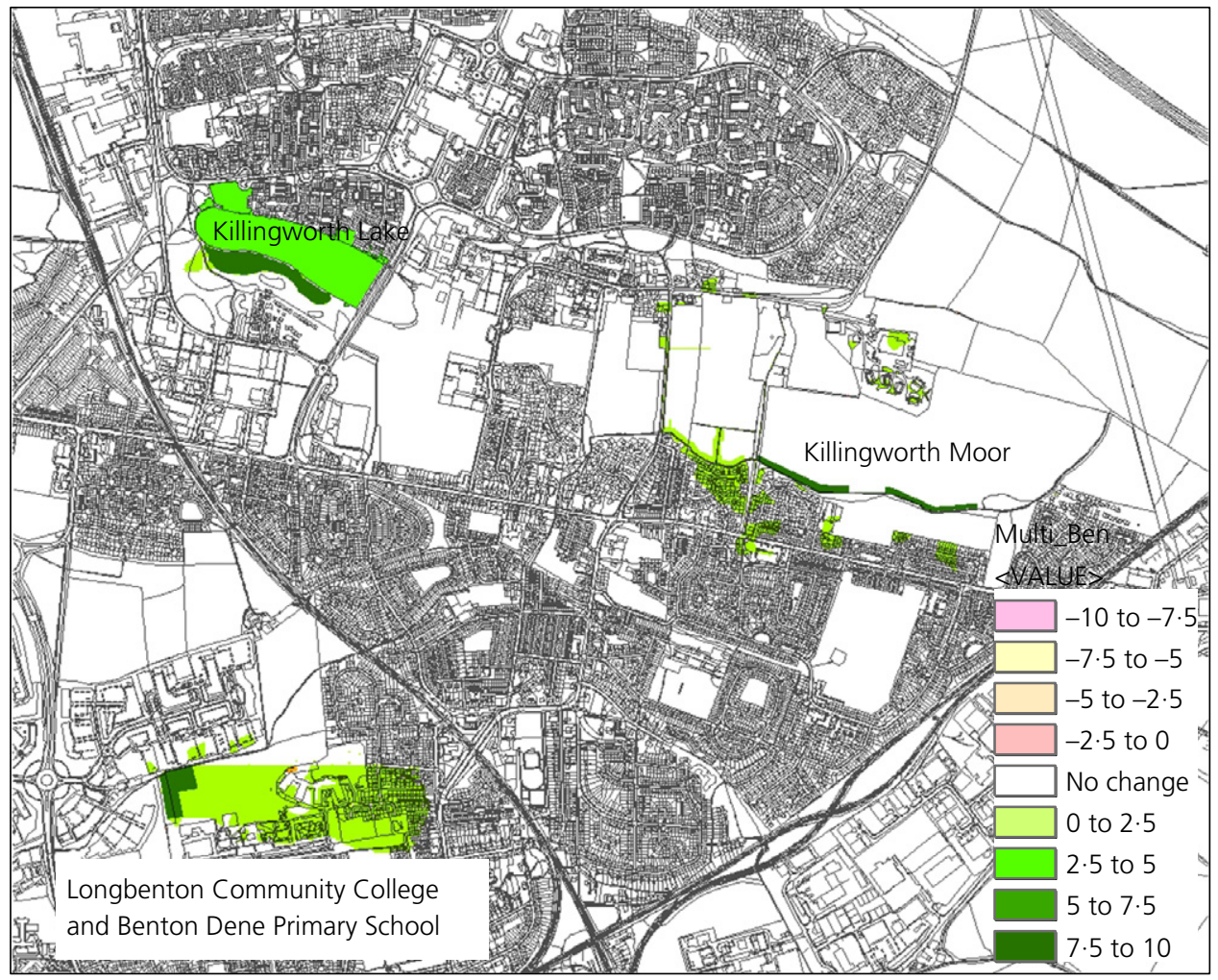

Figure 6. Spatial distribution of the multiple benefit intensity associated with the Killingworth and Longbenton surface water management scheme (non-flood benefits only)

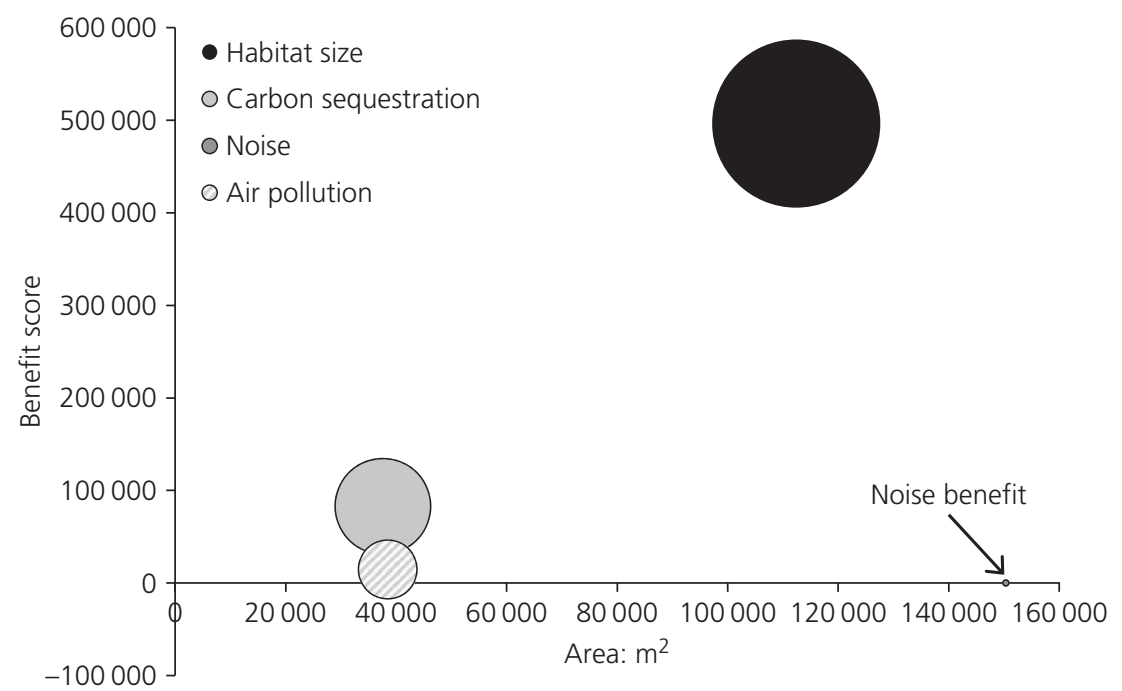

Figure 7. Benefit profile for the Killingworth and Longbenton surface water management scheme; the size of the bubble reflects the effectiveness of the intervention in generating the benefit

when compared with the reference scenario. Similarly, the ability of the greenspace to reduce the propagation of air pollution and absorb $\mathrm{PM}_{10}$ compounds differed depending on the vegetation type. The attenuation basins are thus expected to reduce air pollutant concentrations (sourced from roads) more effectively than the existing natural surfaces. 
Evaluating the multiple benefits of a sustainable drainage scheme in

Newcastle, UK

O'Donnell, Woodhouse and Thorne

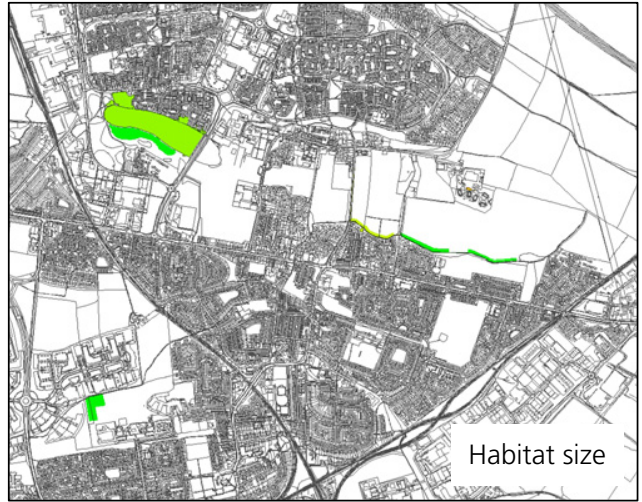

(a)

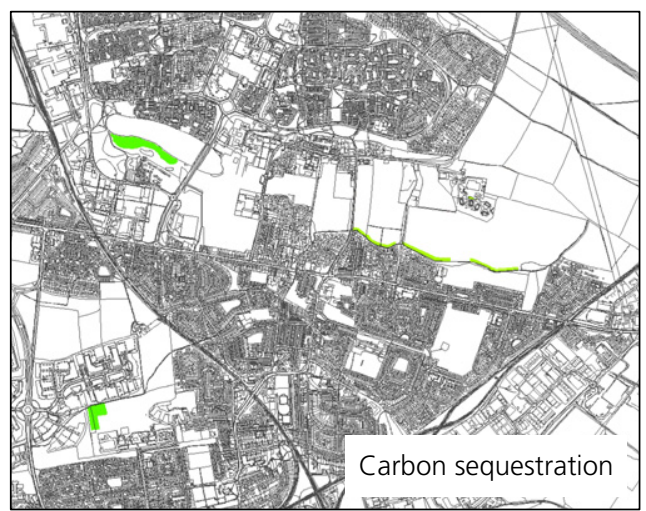

(c)

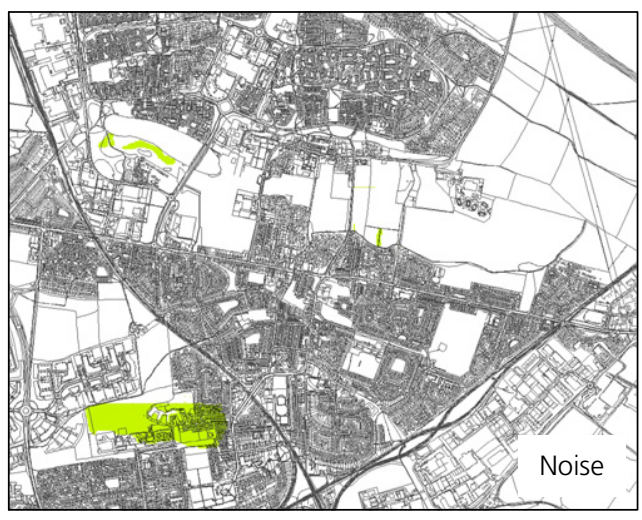

(e)

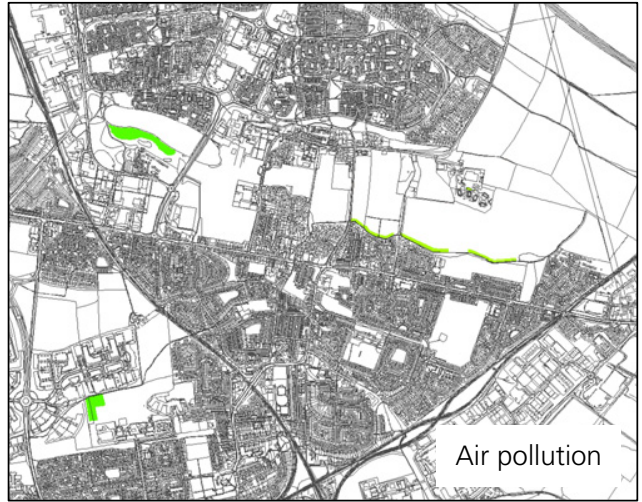

(b)

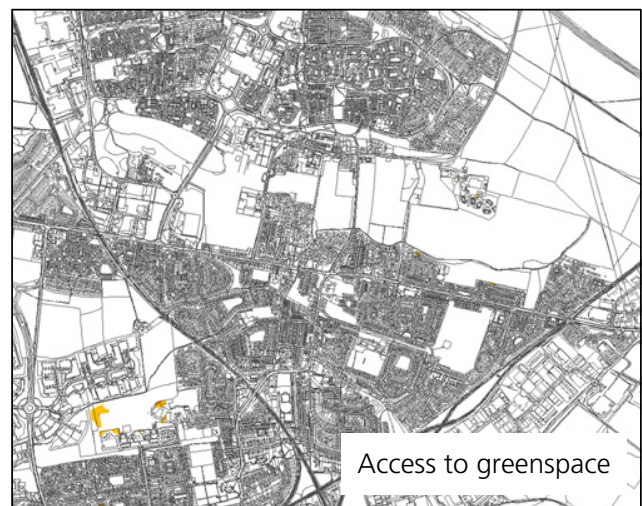

(d)

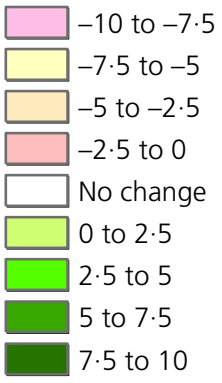

Figure 8. Spatial distribution of the benefit intensity for each benefit category associated with the Killingworth and Longbenton surface water management scheme (non-flood benefits only)

The tool estimates noise based on road type and average traffic levels, and assumes that noise can be reduced by the terrain, buildings and vegetation. This combination of factors led to benefits to noise pollution being primarily observed around the attenuation basin at Longbenton Community College, likely due to a reduction in noise propagation from the dual carriageway to the west (Figure 8(e)).

Access to greenspace was the only category that did not benefit from the interventions (Figure $8(\mathrm{~d})$ ) as no new areas of greenspace were included as part of the scheme and the changes in greenspace type did not affect accessibility. While the attenuation basin at Killingworth Lake may not be directly accessible, the raised path that will be included as part of the scheme is designed to maintain accessibility. The creation of a SuDS amphitheatre around the attenuation basin in the grounds of Longbenton Community College (currently a sports field) will also maintain accessibility, albeit for different activities. The attenuation basins on Killingworth Moor are on private land and in both scenarios are inaccessible. 
Water Management

Volume 171 Issue WM4
Evaluating the multiple benefits of a sustainable drainage scheme in

Newcastle, UK

O'Donnell, Woodhouse and Thorne

\subsection{Potential for blue-green interventions}

The GIS toolbox can also be used to evaluate where interventions may potentially generate the most intense single and multiple benefits. The best opportunities for beneficial interventions in Killingworth and Longbenton are along the highways, pavements and on some of the actual residential buildings (e.g. via green roofs) (Figure 9). Additional interventions on existing greenspace have a lower potential to create large additional multiple benefits as benefit provision is already high at these sites. The individual plots showing the potential for specific benefits to be created provide further information (Figure 9). These plots show that there is greater potential to create some benefits over others and different benefits can be created by modifying different areas. There is

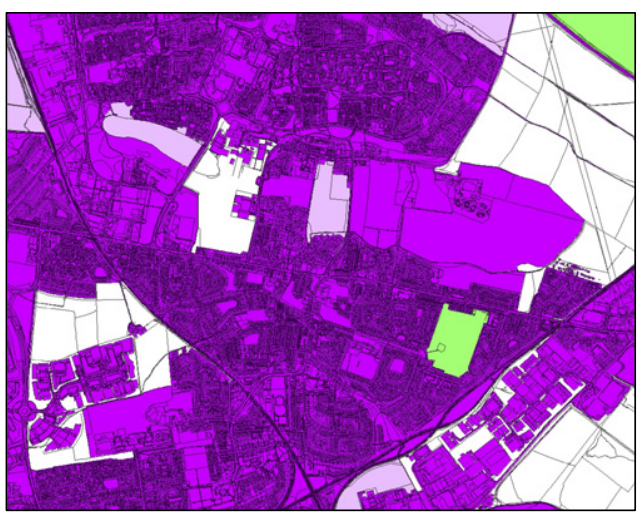

Habitat size

(a)

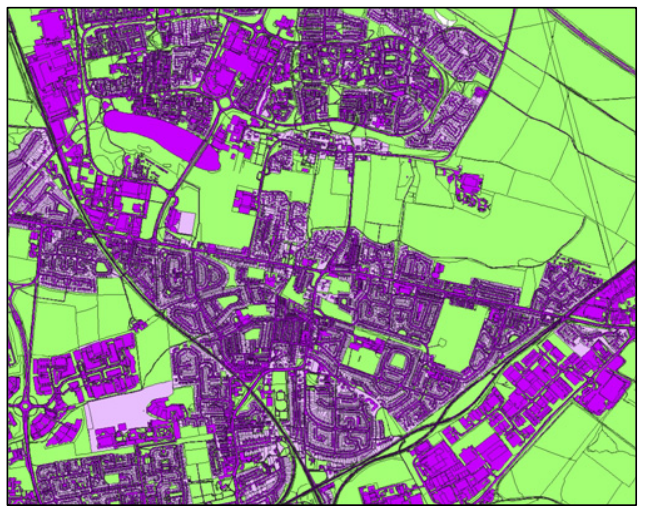

Carbon sequestration

(b)

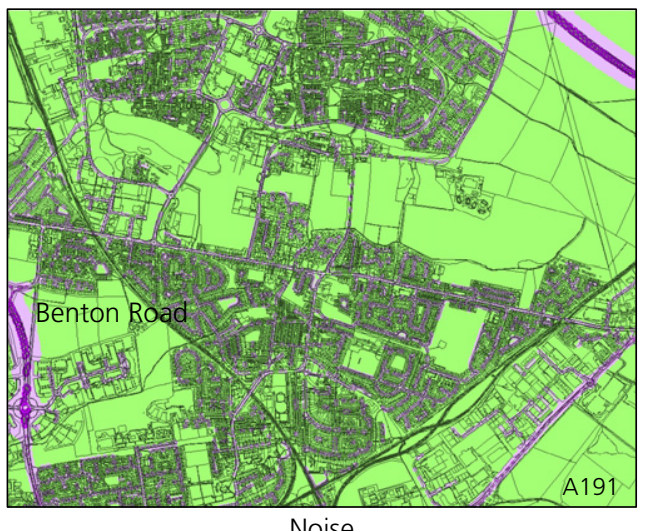

(c)

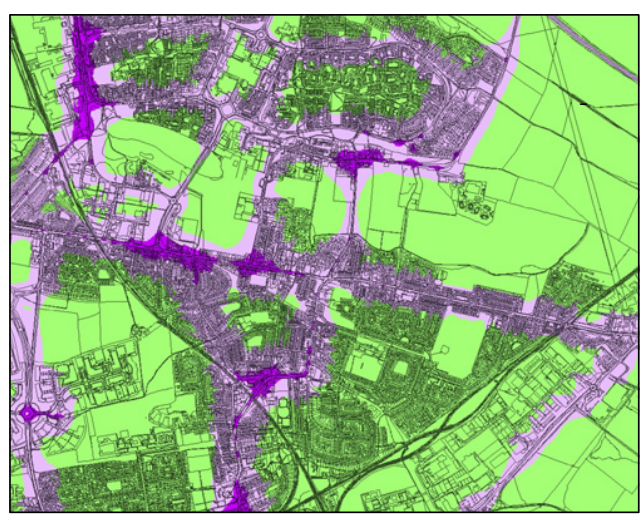

Air pollution

(d)

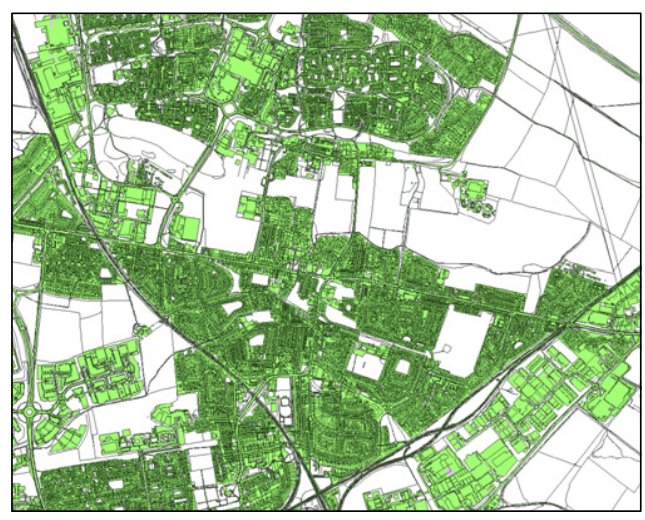

Access to greenspace

(e)

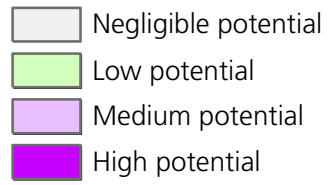

High potential

Figure 9. Spatial distribution of the potential for interventions in Killingworth and Longbenton to generate non-flood benefits 
high potential to improve habitat size by connecting the large areas of existing greenspace with new greenspace in areas currently classified as 'grey' infrastructure (buildings, roads, pavements) (Figure 9(a)). While there may be small pockets of habitats associated with the gardens, trees, parks and sports fields within the residential areas, these are relatively isolated and do not contribute to the connected greenspace network which the tool prioritises when calculating habitat benefits. The potential to improve carbon dioxide sequestration is high in all areas with non-natural surfaces, including paved gardens (Figure 9(b)). There is also potential to change some of the existing greenspace to another type with higher carbon dioxide sequestration rates, such as changing natural surfaces (grassland) to trees, although this level of detail is not currently included in the tool capabilities. There is high potential to reduce noise pollution through interventions along the roads, particularly along Benton Road and the A191 (Figure 9(c)), as the model assumes all noise is derived from traffic. Similarly, the potential to improve air pollution follows the road network as air pollution in the model is derived solely from vehicle emissions (Figure 9(d)). Finally, the potential to improve access to greenspace throughout all residential and commercial areas is low due to the relative proximity of existing greenspace (Figure 9(e)). As greenspace accounts for $47 \%$ of the evaluation site, most residents are within walking distance of greenspace exceeding $500 \mathrm{~m}^{2}$ (fields, natural areas, sports fields, etc.), which is associated with the greatest benefit in the tool. The tool does assume that all greenspace is accessible (unless specified), which may overestimate the general level of accessibility.

\section{Conclusions}

This paper has demonstrated how two complimentary tools - CIRIA's BeST (CIRIA, 2015) and the blue-green cities multiple benefit GIS toolbox (BGC, 2016) - may be used in collaboration to evaluate the multiple benefits (and disbenefits) of BGI or SuDS projects. BeST offers monetisation, qualitative evaluation of several intangible benefits and the ability to calculate benefit accrual over time, while the GIS toolbox illustrates how the benefit intensity may change spatially in response to local environmental factors, benefit effectiveness and where potential interventions would most likely create the greatest impact. The effective visualisation capability of the GIS toolbox and BeST makes them highly suitable for learning and communication activities across organisational boundaries. The tools were trialled in Newcastle and the approach can be adopted for the evaluation of BGI and SuDS in other cities and catchments.

The Killingworth and Longbenton surface water management scheme is predicted to generate significant flood damage reduction benefits of up to $£ 50$ million over a 100 -year period. In addition, the tools suggest that the scheme will improve water quality in local watercourses, increase the attractiveness of the area leading to increases in property prices (near public open greenspace enhancements), increase habitat size and carbon dioxide sequestration, and reduce air and noise pollution. Owing to the large proportion of existing greenspace, the non-flood biophysical benefits accrue primarily at the site of intervention, whereas several regulatory and cultural ecosystem services impact the local and wider area. These benefits will be of interest to other stakeholders aside from Northumbrian Water, the EA and North Tyneside Council who worked in partnership on this project, including health professionals and biodiversity/wildlife departments and organisations. Transportation departments would also be a key stakeholder to involve in discussions about BGI in residential areas owing to the high potential for beneficial interventions along highways and pavements.

Utilisation of these tools for multiple benefit evaluation shows promise as an aid to facilitate partnership working towards wider implementation of multi-functional BGI. The specific benefits that may accrue to the different stakeholders need to first be identified and supported with sound evidence. How BGI may help organisations and departments meet their strategic objectives needs to be communicated clearly. These tools will be of interest to public and private organisations investigating potential partnership working and joint funding of BGI and SuDS projects, and the analyses presented in this paper give an indication of the capabilities. This work focused on the benefit intensity and potential benefits derived from the GIS toolbox and monetised benefits from BeST. Both tools can also identify possible beneficiaries of BGI schemes, either directly through a stakeholder matrix (BeST) or indirectly with the GIS toolbox by inferring stakeholders from the spatial distribution of benefits. Identification of beneficiaries is another critical step in fostering collaborative working between institutions and joint funding of SuDS and BGI projects.

\section{Acknowledgements}

The authors would like to acknowledge Northumbrian Water Group and the Blue-Green Cities Research Consortium, which collectively funded this project. Under the Blue-Green Cities project, this work was supported by the Engineering and Physical Sciences Research Council (grant number $\mathrm{EP} / \mathrm{K} 013661 / 1)$. The authors would also like to thank Malcolm Morgan for help with running the multiple benefits GIS tool, MWH for the BeST evaluation and colleagues at Northumbrian Water for useful discussions and information for this paper. The research data associated with this paper are openly available from the University of Nottingham data repository (http://dx.doi.org/10.17639/nott.57).

\section{REFERENCES}

Ashley R, Lundy L, Ward S et al. (2013) Water-sensitive urban design: opportunities for the UK. Proceedings of the Institution of Civil Engineers - Municipal Engineer 166(2): 65-76, http://dx.doi.org/ 10.1680/muen.12.00046.

Ashley R, Walker L, D'Arcy B et al. (2015) UK sustainable drainage systems: past, present and future. Proceedings of the Institution of 
Civil Engineers - Civil Engineering 168(3): 125-130, http://dx.doi. org/10.1680/cien.15.00011.

BGC (Blue-Green Cities) (2016) Blue-Green Cities research project. See http://www.bluegreencities.ac.uk/bluegreencities/publications/ multiplebenefittoolbox.aspx (accessed 04/09/2016).

Brack CL (2002) Pollution mitigation and carbon sequestration by an urban forest. Environmental Pollution 116: S195-S200.

Casal-Campos A, Fu G, Butler D and Moore A (2015) An integrated environmental assessment of green and gray infrastructure strategies for robust decision making. Environmental Science \& Technology 49(14): 8307-8314.

CIRIA (2015) W045a Benefits of SuDS Tool-BeST. CIRIA, London, UK. See http://www.ciria.org/News/Ciria_news2/New-toolassesses-the-benefits-of-SuDS.aspx (accessed 04/09/2016).

Coutts C (2016) Green Infrastructure and Public Health. Routledge, London, UK.

DfT (Department for Transport) (2012) The Noise Sub-Objective. DfT, London, UK. See http://www.dft.gov.uk/webtag/documents/expert/ pdf/unit3_3_2-noise-05-12.pdf (accessed 05/09/2016).

EA and Ofwat (Environment Agency and Ofwat) (2013) Drainage Strategy Framework: For Water and Sewerage Companies to Prepare Drainage Strategies. EA and Ofwat, Swindon, UK.

Ellis JB (2013) Sustainable surface water management and green infrastructure in UK urban catchment planning. Journal of Environmental Planning and Management 56(1): $24-41$.

Everett G, Morzillo A, Lamond J, Matsler M and Chan F (2015) Delivering green streets: an exploration of changing perceptions and behaviours over time around bioswales in Portland, Oregon. Journal of Flood Risk Management, http://dx.doi.org/10.1111/jfr3. 12225.

Getter KL, Rowe DB, Robertson GP, Cregg BM and Andresen JA (2009) Carbon sequestration potential of extensive green roofs. Environmental Science \& Technology 43(19): 7564-7570.

GVO (Government Valuation Office) (2011) Property Market Report. GVO, London, UK. See http://www.gov.uk/government/ organisations/district-valuer-services-dvs (accessed 05/09/2016).

Hardin PJ and Jensen RR (2007) The effect of urban leaf area on summertime urban surface kinetic temperatures: a Terre Haute case study. Urban Forestry \& Urban Greening 6(2): 63-72.

HM Treasury (2003) The Green Book: Appraisal and Evaluation in Central Government. HMSO, London, UK.

Hoang L, Fenner RA and Skenderian M (2016) A conceptual approach for evaluating the multiple benefits of urban flooding management practice. Journal of Flood Risk Management, http://dx.doi.org/ $10.1111 /$ jfr3.12267.

Jose R, Wade R and Jefferies C (2015) Smart SUDS: Recognising the multiple-benefit potential of sustainable surface water management systems. Water Science and Technology 71(2): 245-251.

Lennon M and Scott M (2014) Delivering ecosystems services via spatial planning: reviewing the possibilities and implications of a green infrastructure approach. Town Planning Review 85(5): 563-587.

Mitchell MG, Bennett EM and Gonzalez A (2013) Linking landscape connectivity and ecosystem service provision: current knowledge and research gaps. Ecosystems 16(5): 894-908.

Morgan M and Fenner R (2017) A spatial evaluation of the multiple benefits of SuDS using blue-green infrastructure. Journal of Water Management, in press.

NCC (Newcastle City Council) (2012) A Stroll Through Ouseburn Parks. Newcastle City Council Report. NCC, Newcastle, UK

Newell JP, Seymour M, Yee T et al. (2013) Green alley programs: planning for a sustainable urban infrastructure? Cities 31: 144-155.

Norton BA, Coutts AM, Livesley SJ et al. (2015) Planning for cooler cities: a framework to prioritise green infrastructure to mitigate high temperatures in urban landscapes. Landscape and Urban Planning 134: 127-138.

NW (Northumbrian Water) (2016) Rainwise. NW, Durham, UK. See http://www.nwl.co.uk/your-home/your-services/Community-ActionPlans.aspx (accessed 08/08/2016).

NWCP (Northumbrian Water Community Portal) (2016) Killingworth and Longbenton; Project Activity. NWCP, Durham, UK. See http://www.nwlcommunityportal.co.uk/Projects/killingworth-andlongbenton/Activity (accessed 05/09/2016).

O'Donnell E, Lamond J and Thorne C (2017) Recognising barriers to implementation of blue-green infrastructure: a Newcastle case study. Urban Water Journal 14: 1-8.

Penning-Rowsell E, Priest S, Parker D et al. (2014) Flood and Coastal Erosion Risk Management: A Manual for Economic Appraisal. Routledge, London, UK.

Stovin VR, Moore SL, Wall M and Ashley RM (2013) The potential to retrofit sustainable drainage systems to address combined sewer overflow discharges in the Thames Tideway catchment. Water and Environment Journal 27(2): 216-228.

Thorne CR, Lawson EC, Ozawa C, Hamlin S and Smith LA (2015) Overcoming uncertainty and barriers to adoption of blue-green infrastructure for urban flood risk management. Journal of Flood Risk Management, http://dx.doi.org/10.1111/jfr3.12218.

TW (Thames Water) (2016) Sustainable Drainage Schemes. TW, Reading, UK. See http://www.thameswater.co.uk/cr/ Sustainabledrainage/Sustainableurbandrainagesystems/index.html (accessed 08/08/2016).

Tzoulas K, Korpela K, Venn S et al. (2007) Promoting ecosystem and human health in urban areas using green infrastructure: a literature review. Landscape and Urban Planning 81(3): 167-178.

UKNEA (UK National Ecosystem Assessment) (2011) UK National Ecosystem Assessment: Understanding Nature's Value to Society. Synthesis of Key Findings. UKNEA, Cambridge, UK.

Woods Ballard B, Wilson S, Udale-Clarke $\mathrm{H}$ et al. (2015) CIRIA Report C753 The SuDS Manual. CIRIA, London, UK. See http://www. ciria.org/Memberships/The_SuDs_Manual_C753_Chapters.aspx (accessed 04/09/2016).

WW (Welsh Water) (2016) Rainscape. WW, Treharris, UK. See http://www.dwrcymru.com/en/My-Wastewater/RainScape.aspx (accessed 08/08/2016)

\section{How can you contribute?}

To discuss this paper, please email up to 500 words to the editor at journals@ice.org.uk. Your contribution will be forwarded to the author(s) for a reply and, if considered appropriate by the editorial board, it will be published as discussion in a future issue of the journal.

Proceedings journals rely entirely on contributions from the civil engineering profession (and allied disciplines). Information about how to submit your paper online is available at www.icevirtuallibrary.com/page/authors, where you will also find detailed author guidelines 